\title{
Um estudo da "Ética" de Spinoza: A vida ideal como união consciente com Deus
}

\author{
JOACHIM, H. H. A study of the Ethics (Ethica ordine geometrico \\ demonstrata). Oxford: Clarendon Press, 1901, Book III, \\ cap. 4, p. 292-309.
}

Gionatan Carlos Pacheco (Tradutor)

http://orcid.org/0000-0003-1189-4858 - E-mail: gionatan23@gmail.com

\section{§ 1 Introdução}

Com a abordagem da vida moral como a vida da razão, a principal tarefa da Ética está em certo sentido concluída. Spinoza aplicou sua teoria metafísica geral à natureza do homem e mostrou como os lados emocional e cognitivo dessa natureza são interdependentes e consequências necessárias da ordem das coisas. Ele estabeleceu o ideal da razão com base na autorrealização da mente: ele mostrou como o homem, ao viver a vida da religião e do dever — manifestando nobreza e força de espírito - está realizando seu eu mais verdadeiro e, portanto, é livre. A moralidade não é um fardo enfadonho, que devemos suportar em vista de recompensa. A única escravidão é a sujeição às paixões: e a liberdade da moralidade nos livra delas. A vida de virtude é a vida de poder. Viver é ser ou tornar-se nós mesmos. Viver uma vida de paixão é nos afundarmos nas forças externas da "ordem comum da natureza", é cessar de ser qualquer coisa que tenha um caráter próprio".

Essas conclusões são independentes do que se segue. Elas permanecem inabaláveis, qualquer que seja nossa visão quanto à existência temporal do homem. Elas ainda seriam verdadeiras, mesmo que o eu que conquistamos fosse tão dependente das condições locais e temporais que nós fossemos reais em nenhum outro sentido do que aquele em que as coisas da experiência imaginativa são reais. Se, fora de nossa existência como membros da ordem comum

1 Cf. E5p41 e E5p41esc. [NT: A referência às passagens da Ética seguirá a seguinte notação: de início, seguido da letra $E$ que refere a obra, um numeral arábico que indica em qual das cinco partes se encontra a passagem, seguido de uma abreviação da natureza da passagem: def - definição, $a x$ - axioma e $p$ - proposição. Na sequência dessa abreviação um numeral arábico referente a passagem. A isso, no caso de escólios seguirá a abreviatura esc, em corolário - cor, em demonstração - dem, em explicação - expl, seguidos, quando for o caso, de seus respectivos números.]. 
da natureza, nós não somos nada; e se, antes do nascimento, nós em nenhum sentido éramos - se, após a morte, nós em nenhum sentido seremos - ainda, durante esta nossa vida, as posições que Espinosa estabeleceu permanecem firmes. Durante a vida, podemos e devemos nos esforçar para realizar nosso eu mais essencial: e, neste esforço, nós - uma vez que estamos seguindo a tendência inevitável de nossa natureza - estamos nos tornando tão reais quanto realidade temos em nós para o sermos: mesmo que essa realidade deva permanecer uma mera realidade imaginativa, isto é, a realidade das coisas, cuja individualidade deve ocorrer em um lugar e tempo particular, e durar por um período definido.

Espinosa, de fato, estabeleceu mais do que isso. Em nosso conhecimento científico, estamos nos movendo no terreno da verdade. E, até aí, nós somos eternos ou independentes de condições temporais. Mas a ciência permanece abstrata, e o nós da ciência é - para tudo o que Spinoza mostrou - uma mente-corpo imersa na natureza geral do Pensamento e da Extensão, ou pelo menos não mais individualizada do que a infima species, o homem. O homem livre ou agente moral pode - pelo que sabemos - permanecer, no que diz respeito ao seu ser individual, fora do mundo da verdade ou realidade eterna. Ele pode dever seu ser enquanto essa pessoa às barreiras imaginativas, das quais ele não pode se libertar completamente. Ele pode, por assim dizer, viver a vida racional por meio de uma realidade permanente e eternidade emprestadas, sem ele mesmo ser real ou eterno².

Na seção conclusiva da Ética (E5p20-40), Spinoza se esforça para concluir a sua concepção do ideal humano. Ele tenta mostrar que existe um grau de autorrealização do homem, no qual a mente é eterna ou totalmente real: que, no ponto mais alto que alcançamos, estamos realmente fruindo em nós mesmos a plenitude do ser, que é a marca da realidade completa.

Em linhas gerais, a posição de Spinoza é esta: - no pensamento mais completo de que nós, como inteligências, somos capazes, nosso pensamento é o pensamento de Deus; e o pensamento de Deus é Deus pensando na medida em que constitui a essência de nossa mente, isto é, o pensamento de Deus é o nosso pensamento. Essa unidade de nosso ser inteligente com Deus nos funde no pensamento divino, e eo ipso nos caracteriza de forma mais completa, ou nos dá nosso eu. E nessa transfusão de nosso ser pensante pelo ser de Deus, somos reais com a realidade divina, ou Deus é real em, e como, nós: isto é, nós somos eternos. No brilho daquela autorrealização que é ao mesmo tempo a identidade de todos os seres com Deus, bem como a distinção mais completamente caracterizada de todos os seres de Deus e uns dos outros, nossa mente une ou funde em si todo o nosso ser. Não há mais uma distinção entre uma consciência emocional e uma cognitiva. A consciência cognitiva é emocional e a emocional é cognitiva, ou melhor, também a consciência é transformada. Portanto, podemos dizer tanto "nosso pensamento é o pensamento de Deus e o pensamento de Deus é o nosso próprio eu": quanto "nossa consciência de nossa felicidade, ou nosso amor - que flui da compreensão dessa felicidade e sua causa — é o amor de Deus por si mesmo e por nós; e o amor de Deus por si mesmo é o nosso amor por Deus".

\section{$\S 20$ conceito de eternidade}

Spinoza não é muito consistente em seu uso do termo duração ${ }^{3}$ Ele está ansioso para evitar o mal-entendido que confunde eternidade com quantidade indefinida de tempo: e, por-

2 Cf. (JOACHIM, 1901, pp. 265-sqq).

3 Essa inconsistência parece ser devida à sobrevivência parcial em Spinoza (especialmente em seus escritos anteriores) do uso escolástico contemporâneo da palavra; cf. (GRZYMISCH, 1898, pp. 42; 45). 
tanto, frequentemente se recusa a predicar duração para aquilo que é eterno ${ }^{4}$. Quando é assim, ele identifica duração com persistência no tempo.

Por outro lado, tempo é, para Spinoza, o resultado de uma limitação da duração: a concepção de tempo é um auxílio imaginativo que nos permite retratar a persistência ou a existência permanente. O tempo secciona a duração em porções, destruindo assim sua integridade ou continuidade e dando-Ihe um começo, um fim e estágios. Quando este for o caso, duração é o termo geral, do qual existência eterna e existência temporal são formas - não exatamente espécies, pois a primeira é a duração adequada ou inteligentemente apreendida, enquanto a última é sua forma confusa, parcial ou retrato imaginativo (JOACHIM, 1901, p. 31).

É necessário observar esta inconsistência, porque, em E5p20esc, Spinoza fala da "duração da mente sem relação com o corpo", onde ele quer dizer a eternidade da mente: enquanto em outro lugar (e. g., E5p23esc.) ele identifica duração com tempo e, portanto, exclui ambos da concepção da eternidade da mente.

Espinosa usa uma vez a expressão imortal para a mente como equivalente eterno (E5p41esc). O fato dele fazer isso apenas uma vez provavelmente se deve (como sugere Pollock) à sua ansiedade em evitar as associações equivocadas de palavras. Pois, de uma coisa não pode haver dúvida: Spinoza não pretendia estabelecer para a alma humana uma vida pós-morte infinitamente-prolongada em outro mundo ${ }^{5}$. Essa caricatura popular do conceito filosófico de eternidade é tão estranha a todo o pensamento de Spinoza que não podemos nem por um momento lhe atribuir. Ela está associada às próprias concepções contra as quais toda a obra de Spinoza é um protesto firme - os conceitos de Deus como legislador e juiz, e da felicidade como a recompensa da virtude.

É verdade que, em um lugar, Spinoza usou uma expressão que é extremamente enganosa. "Com isso," ele diz"concluí meu relato de tudo o que diz respeito à vida presente"(E5p20esc). Mas, mesmo que esqueçamos que esta vida presente naturalmente significaria para Spinoza nossa vida na medida em que somos "imaginativos", e implicando como que a sua antítese (não uma vida futura do mesmo tipo, mas) uma vida atual de um tipo diferente, ou seja, nossa vida na medida em que somos inteligentes, não podemos dar ênfase a esta passagem. Em vista do que Spinoza fala sobre a eternidade ${ }^{6}$ da mente, devemos considerar esse enunciado como um deslize momentâneo: pois senão persistiremos em interpretá-la como uma vida futura no sentido de que aqui e agora somos mortais, mas, algures e além, revestidos de imortalidade.

Apesar de um lapso ocasional no uso mais amplo de duração ${ }^{7}$, Spinoza já havia, nos Cogitata Metaphysica [Pensamentos Metafísicos], claramente distinguido entre eternidade e duração indefinida, e fixado a sua terminologia para marcar esta distinção.

Ele começa com a divisão entre ser cuja essência envolve existência (isto é, Realidade substancial) e ser cuja essência envolve apenas a possibilidade de existência (isto é, Realidade modal, ou, do ponto de vista dos Cogitata Metaphysica (I, 4; II, 1 e 10), ser "criado".

As coisas criadas, na medida em que sua existência possível está sendo atualmente realizada, perduram ou duram. A comparação de sua duração com a das coisas que têm um movimento definido e determinado resulta em tempo: o ens rationis ou modus cogitandi (isto é, modus imaginationis), que mede a duração. A duração é realmente idêntica à existência total

\footnotetext{
${ }^{4}$ Cf. e.g. E1def8expl.

${ }^{5}$ Cf. (POLLOCK, 1899, p. 270); e o excelente artigo de A. E. Taylor (1896), ao qual Pollock se refere.

${ }^{6}$ Ou seja, na Ética. Pois, no Breve Tratado, Spinoza não se libertou completamente das confusões comuns que ele ataca. Para o desenvolvimento do conceito de eternidade de Spinoza, ver Grzymisch (1898), especialmente p. 7-9, 16, e p. 41-sqq.

${ }^{7}$ Cf. e.g. Carta 12 e E5p20esc.
} 
- diferentemente da essência - de uma coisa criada: diminua ou aumente sua duração e você diminuirá ou aumentará sua existência. É apenas uma distinção lógica que as separa ${ }^{8}$.

Quando falamos de coisas que existiram "desde toda a eternidade" (ab aeterno), estamos usando mal o termo eternidade. Estamos confundindo a eternidade com uma duração indefinida: uma duração sem começo. A eternidade não pode ser expressa em termos de duração, mesmo que seja uma duração infinita, isto é, sem começo ou fim ${ }^{9}$.

Mas Deus é corretamente dito ser eterno. Pois a essência de Deus é una com sua existência: e, portanto, não se pode dizer que Deus tenha duração, visto que a duração é a existência concebida separadamente da essência. Se Deus tivesse duração, sua duração aumentaria dia a dia. Ele se tornaria mais real com o passar do tempo: estaria, por assim dizer, continuamente criando a si mesmo. Mas o ser de Deus - sua essência ou existência - é infinito, isto é, completo atualmente agora e sempre. A eternidade de Deus, então, significa simplesmente sua completude infinita. É sua existência, que é sua essência, e é total e absolutamente atual; não parcialmente real agora, e parcialmente prestes a ser. Queremos dizer a mesma coisa quando falamos da natureza essencial de um triângulo como uma verdade eterna. É o que é total e completamente e não vem a ser. Não é mais real agora do que era nos dias de Adão: nem durou mais tempo agora do que então.

Portanto, eternidade é a própria essência de Deus, na medida em que envolve a existência necessária (E5p30dem). A eternidade expressa a necessidade atemporal de ser, e não tem nada a ver com a duração de um tempo infinitamente longo. "Não há quando, nem antes e depois, na eternidade" (E1p33esc2).

Do ponto de vista da Ética, todas as coisas são eternas, na medida em que sua existência é a consequência necessária da essência de Deus. Como concebidas em Deus, todas as coisas são modos eternos e infinitos; são atualmente reais com a necessidade atemporal do ser eterno de Deus ${ }^{10}$. As coisas são ditas atuais tanto na medida em que existem em um tempo definido e em um lugar definido, e assim sua existência é sua duração, quanto na medida em que as concebemos como estando contidas em Deus e decorrendo da necessidade da natureza divina. Neste último sentido, as coisas são reais ou verdadeiras, na medida em que as concebemos "sob o aspecto de eternidade", e na medida em que suas ideias envolvem a essência eterna e infinita de Deus (E5p29esc).

Na seção final da Quinta Parte da Ética, Spinoza está imediatamente ocupado com a eternidade da mente humana. Porém, embora a mente humana difira em natureza essencial e em grau de realidade de outros modos, e embora, assim, sua eternidade difira da deles, apesar disso, todos os modos, na medida em que são concebidos em sua necessária dependência de Deus, são atemporalmente atuais ou eternos ${ }^{11}$.

\section{$\S 3$ A eternidade da mente humana}

Cada modo, em sua sequência necessária da natureza de Deus, tem sua realidade dependente da essência de Deus, ou seja, é eterno. Cada modo - talvez possamos expressá-lo

\footnotetext{
${ }^{8}$ Pensamentos Metafísicos, l, 4, 2“[...] durationem a tota alicuius rei existentia non nisi Ratione distingui [entre a duração e a existência total da não há senão distinção de Razão]".

9 Cf. E1def8expl.

${ }^{10}$ Cf. E5p30dem; Carta 12; ver JOACHIM, 1901, p. 27-sqq e pp. 76-sqq.

${ }^{11}$ Contrastar com Pollock (1989, p. 275-sqq). Seus argumentos parecem-me cair por terra, quando nos lembramos (i) de que Espinosa confessadamente confina-se nas últimas partes da Ética à mente humana (cf. e. g., Prefácio de E2 e Prefácio de E5); (ii) de que, para Spinoza, existem diferenças de grau e de tipo na realidade dos modos (cf. JOACHIM, 1901, p. 73-sqq).
} 
- é real na medida em que o Todo vive e se move nele: e o que é real é necessariamente atual, isto é, é ele próprio total e inalterável, sem desenvolvimento, degradação, ou processo de qualquer tipo. Agora, o grau ou tipo de tal atualidade (a natureza da eternidade) que qualquer modo desfruta, depende inteiramente do grau ou tipo de realidade do modo em questão. O problema é - Como o Todo vive e se move neste modo? Quanto de realidade ele contém? Em que grau e em que sentido ele participa da natureza divina?

Saber responder a essas questões implica o que Spinoza chama de scientia intuitiva (JOACHIM, 1901, pp. 180-sqq). E a posse deste conhecimento com respeito ao nosso próprio ser modal é o desfrute de nossa felicidade suprema. Pois é nessa "cognitio unionis, quam mens cum tota natura habet" [conhecimento da união que a mente tem com toda a natureza], que Spinoza encontra a completa autorrealização do homem (Ibidem, p. 4, nota 1).

Vejamos como Spinoza desenvolve esse conceito. A categoria de todo e partes é, como sabemos, inadequada para expressar a natureza das coisas (Ibid., pp. 42-3, 89-sqq). Os modos não são partes da substância. A unidade dos modos em Deus é mais íntima do que a unidade das partes em um todo. A Substância também não é uma totalidade de modos. Os modos sequer podem ser concebidos à parte de Deus. Deus não está apenas implícito (implied) nos modos, como um todo está implícito em suas partes. Deus é os modos, e os modos nada são, senão na medida em que são expressões de Deus. É a separação dos modos de Deus (como se fossem partes de um todo) que causa a compreensão inadequada da consciência imaginativa, para a qual a Realidade se torna um mundo de coisas finitas.

Temos, então, que lembrar que a realidade de todos os modos é Deus. É o pensamento de Deus que é nossa mente, a extensão de Deus que é nosso corpo, a autoafirmação eterna de Deus ou "poder" que é nosso ser atual.

Ao mesmo tempo, a completude de Deus, sua unidade absoluta, não é abstrata, mas concreta. Os modos que expressam seu ser, expressam-no de todas as maneiras: sua unidade completa se revela em completa multiplicidade. Na unidade absoluta de todas as coisas em Deus, todas as coisas são mais plenamente caracterizadas, distintas, ou seja, individuais. É tarefa da filosofia - o conhecimento ideal que Spinoza chama scientia intuitiva - atingir a visão clara da individualidade íntima ou da essência característica de todas as coisas em Deus. Essa visão é a consumação daquele pensamento claro que começa na ciência. E é o resultado de uma inferência "que começa com a ideia adequada da essência real de alguns dos Atributos de Deus, e prossegue para o conhecimento adequado da essência das coisas" (Ibid., pp. 180-sqq).

Spinoza afirma ter cumprido essa tarefa no que diz respeito à mente humana, isto é, ter mostrado "como nossa mente segue em sua essência e existência da natureza divina, e está em dependência ininterrupta de Deus" (E5p36esc). Ele afirma, portanto, ter mostrado na Ética, no que consiste a individualidade característica da mente humana, ou qual é o grau e tipo de sua realidade e eternidade.

Nossa mente, lembramos, era considerada como um complexo de ideias, o lado ideal de um complexo de corpúsculos extensos ${ }^{12}$. O que chamamos de nossa mente a qualquer momento é um composto de ideias adequadas e inadequadas: isto é, é parcialmente nosso eu e, em parte, as ideias emprestadas e mutiladas, que são completas no pensamento de Deus, mas no pensamento de Deus constituem outros eus junto com o nosso. Essas ideias confusas - qua confusas - não são realmente nossas. Não constituem a natureza essencial da nossa mente; constituem a nossa-mente-no-seu-ambiente. E não indicam tanto o que somos, mas o que não

\footnotetext{
${ }^{12}$ Cf. (JOACHIM, 1901, p. 131).
} 
somos; revelam os nossos limites, as bordas irregulares (torn edges) que nos fazem finitos ${ }^{13}$. Elas são os sinais de nossa impotência ou incapacidade de nos sustentarmos por nós mesmos, nossa dependência da ordem comum da natureza - o contexto que sustenta nossa existência temporal ou imaginativa. Se pudéssemos nos livrar da influência externa, nossa a mente viria a si mesma como ideias adequadas: como o pensamento de Deus, na medida em que esse pensamento constitui a essência de nossa mente e nada mais. Na morte, somos deixados livres. Pois, com a dissolução do nosso corpo, a interação dos corpos externos com o nosso deve cessar; e as consequentes ideias confusas (que são o lado ideal dessa interação) devem desaparecer. Não podemos nem imaginar nem lembrar (nós não estamos sujeitos à influência da associação), exceto enquanto nosso corpo dura, ou seja, existe no tempo e no espaço (E5p21). Mas a morte é apenas uma maneira pela qual, então, chegamos a nós mesmos. A condição essencial é que devemos pensar com clareza e adequação, e pensar apenas com clareza e adequação. Em outras palavras, a natureza essencial de nossa mente é o intelecto; nós somos reais e completamente nós mesmos na proporção em que nós somos consciência inteiramente clara.

Para Spinoza, portanto, a essência da mente humana é o intelecto. Ela é totalmente ela mesma, quatenus intelligit [enquanto intelige] - na medida em que compreende ou pensa adequadamente. Mas quando pensamos adequadamente, Deus está pensando em nós na medida em que constitui apenas a nossa mente. Em nosso ser essencial, portanto, percebemos nossa unidade com Deus, ou Deus está se expressando em nós. E isso significa que, em nossa consciência clara e adequada, somos eternos: atingimos o tipo de eternidade que caracteriza a natureza humana. Nesse sentido, nossa mente - enquanto um pensamento adequado e significativo no contexto do pensamento de Deus - é parte do intelecto completo de Deus ${ }^{14}$.

Contudo, é necessário mais para completar o conceito de Spinoza. A mente, como um modo do Pensamento, é a expressão ideal de um modo da Extensão; e é assim para si mesmo, uma vez que todo modo do Pensamento é, como tal, voltado para si mesmo ${ }^{15}$.

Em nossa existência temporal, nossa mente é a expressão ideal de nosso corpo atualmente (isto é, temporalmente) existente, e nossa autoconsciência é o sentimento de nós mesmos como esta peça animada de Extensão. Mas em nossa existência essencial ou real, nossa mente é o conhecimento adequado de nosso corpo, e nossa autoconsciência é a compreensão adequada de nós mesmos como um modo eterno de Deus: isto é, a ideia adequada, que é a essência de nossa mente, é a expressão ideal de nosso corpo em sua natureza verdadeira ou essencial, nomeadamente, como um modo eterno da Extensão ${ }^{16}$. E a ideia dessa ideia é a consciência reflexiva desse nosso verdadeiro eu.

Já vimos que o conhecimento científico implica como seu centro ou base "um eu, que é constituído pelas propriedades permanentes e necessárias comuns a todos os modos de Extensão e de Pensamento"17. Conhecimento filosófico - scientia intuitiva - implica um eu, que é ao mesmo tempo permanente e necessário, e individual. Nós, como sujeitos do conhecimento filosófico, somos uma mente que se apreende como a ideia da natureza essencial de nosso corpo. Em outras palavras, o eu do conhecimento completo, é uma individualidade que tem um ser universal, necessário e permanente em sua unidade com Deus, porém é ainda concreto e unicamente caracterizado. Porque estamos em unidade com Deus, porque Deus se expressa em nós, não estamos perdidos na universalidade abstrata dos objetos da ciência, mas

\footnotetext{
${ }^{13}$ Cf. e.g. E3p3esc.

14 (JOACHIM, 1901, pp. 92-3); E5p40esc; E2p11cor.

${ }^{15}$ Ibidem, pp. 132-sqq, p. 257, nota 4.

${ }^{16}$ Cf. E5p22.

17 (JOACHIM, 1901, p. 178).
} 
chegamos a uma personalidade rica e real. Porque somos nós mesmos, somos participantes plenos da natureza divina. Porque nós nada mais somos do que o conhecimento adequado de Deus sobre a natureza essencial do nosso corpo, realizamos plenamente nosso eu, ou ainda, fruímos de nosso caráter individual em sua plenitude ${ }^{18}$.

Visto que "é necessariamente dada uma ideia em Deus, que expressa a essência deste e daquele corpo humano sob a forma de eternidade" ${ }^{19}$, segue-se que, em certa medida, todo homem é eterno. "A mente humana não pode ser totalmente destruída com o corpo, mas algo dela, que é eterno, permanece" (E5p23). Essa proposição coloca a questão como sobrevivência após a morte, e como se a parte eterna da mente fosse um espírito desencarnado. Mas segue-se da posição de Spinoza (como vimos) que todo homem é eterno até certo ponto no sentido spinozano estrito de eterno.

Cada homem, talvez em algum grau infinitesimal, compartilha da consciência clara de si mesmo e de todas as coisas, que é a sua eternidade. Pois esta é a característica da humanidade $^{20}$. E a natureza essencial do corpo de cada homem é um modo eterno da Extensão de Deus; e é, portanto, o ideatum de uma ideia eterna do Pensamento de Deus, que é a natureza essencial da mente daquele homem. Mas existem infinitos graus na realidade de diferentes homens, infinitos graus na plenitude da essência de seus corpos; graus infinitos, portanto, no ser eterno das mentes de diferentes homens.

Qual é a natureza dessa gradação? O princípio geral é que uma coisa está no seu melhor (ou perfeito) estágio, na proporção em que ela se afirma e sustenta a si mesma. Uma coisa é mais real, na verdade, quanto mais isso ocorre. O homem ideal (o melhor ou o mais abençoado) é aquele cuja maior parte da mente é conhecimento adequado, ou que é eterno ${ }^{21}$. Pois a parte eterna de nossa mente é sua melhor parte: somos ativos na medida em que entendemos, e quanto mais uma coisa é ativa (e quanto menos uma coisa é passiva), mais perfeição ela tem (E5p40 e E5p40cor). Consequentemente, à medida que alcançamos o conhecimento científico e filosófico, estamos menos sujeitos a emoções prejudiciais, bem como temos menos medo da morte (E5p38). E uma vez que o grau de nossa realidade mental é a expressão ideal de nossa perfeição corporal, "aquele que tem um corpo capaz de muitas atividades tem uma mente, da qual a maior parte é eterna" (E5p39).

Podemos, até certo ponto, preencher essas indicações a partir do ensino geral da Ética. Nosso eu é um conhecimento claro, bem como tudo que dele depende, ou nele está envolvido. Nosso eu, portanto, será muito ou será pouco, nossa individualidade dotada de valou ou não, nossa eternidade cheia ou vazia, conforme nós - corpos e mentes - sejamos desenvolvidos e disciplinados "segundo a ordem do intelecto", ou não desenvolvidos e indisciplinados, se à mercê da "ordem comum da natureza". No que diz respeito ao desenvolvimento do corpo, a Ética é quase silenciosa: o assunto foge ao seu âmbito, porém, no que diz respeito ao desenvolvimento da mente, temos materiais completos no esboço do homem livre e no cumprimento dos três graus de conhecimento. Não há necessidade de repetir o ensinamento de Spinoza: mas podemos tentar resumir sua principal afirmação. O homem cujo eu é mais real, cuja individualidade eterna é mais concreta e valiosa, é aquele cuja vida é uma esforço inabalável em direção ao conhecimento claro; não o conhecimento da mera teoria, mas o conhecimento que informa

\footnotetext{
${ }^{18}$ Cf. Ibidem, pp. 243-sqq.

${ }^{19}$ E5p22 (grifos meus); cf. E2p8cor e E2p8esc.

${ }^{20} \mathrm{~A}$ passagem na Carta 19 não deve ser pressionada indevidamente. Mesmo o criminoso, "que serve a Deus sem querer e é consumido no serviço", não está absoluta e inteiramente sem um conhecimento claro de si mesmo e de sua função. Caso contrário, ele não seria humano de todo.

${ }^{21}$ Cf. e.g. E5p31esc, E5p38esc.
} 
e vitaliza a conduta: o conhecimento que, para Sócrates e Platão, era idêntico ao bem. Não é uma vida de ociosidade visionária, de contemplação mística. É uma vida de intensa atividade cheia de deveres e prazeres de uma existência multifacetada: a vida de todos os dias, mas não vivida com um espírito cotidiano. Pois a atividade de tal vida não é a passagem inquieta de interesse em interesse, mas a expressão serena de um único propósito. A consciência do significado desse propósito é o espírito que anima a conduta do homem livre: e no conhecimento de seu cumprimento, ele está em perfeita posse de si mesmo.

Na realização de nós mesmos como intelectos, nossa natureza emocional foi absorvida. Na medida em que nós entendemos, nós somos reais: não estamos mais em transição e, portanto, não somos mais seres emocionais. Porém, embora não tenhamos consciência de aumentar (e menos ainda de diminuir) a vitalidade, estamos intensamente conscientes da vitalidade real. A essa consciência Spinoza dá o nome de "felicidade" - beatitudo - a consumação da laetitia (E5p33esc). E na consciência de nossa felicidade, estamos necessariamente também conscientes de Deus como sua causa: isto é, necessariamente amamos a Deus, na medida em que entendemos seu ser eterno. Este "amor", visto que se baseia no intelecto, e não na apreensão imaginativa, pode ser chamado de "amor intelectual a Deus" (E5p32cor).

Podemos expressar o estado em que atingimos o nosso ser mais completo, em termos desse amor a Deus. O que era verdade sobre nossa autorrealização perfeita como conhecimento completo, é assim também verdade sobre o amor a Deus. Amamos a Deus com um amor que é eterno, porque o nosso amor a Deus é Deus que se ama em nós (E5p36): assim como conhecemos Deus sob a forma da eternidade, porque o nosso entendimento de Deus é Deus pensando-se em (ou como) nós. A mente, em seu conhecimento de Deus, é uma parte do conhecimento completo de Deus dele mesmo. E a mente, em seu amor a Deus, é parte do amor completo de Deus por si mesmo (E5p36).

Este "amor constante e eterno a Deus, que é o amor de Deus pelos homens", é a nossa salvação, felicidade ou liberdade. É a paz de espírito, que as Escrituras corretamente chamaram de "A Glória de Deus" (E5p36esc).

\section{Revisão}

Se nossa interpretação de Spinoza estiver correta, o que exatamente ele provou do homem?

A assim chamada individualidade da experiência imaginativa mostrou-se ilusória e desapareceu. Nosso eu não é o conjunto único de sentimentos ligados à associação única de corpúsculos, que aparecem juntos aqui e agora como a resultante da causalidade do complexo indefinido de coisas finitas. Coisas neste sentido da palavra - objetos particulares de experiência sensível; e os sujeitos de tal experiência, eles próprios os objetos de outra experiência sensível - não têm realidade como tais, não são o que professam ser. Sua autossuficiência, singularidade e distinção entre si são ilusórias. Elas passam umas pelas outras, e os limites que parecem marcá-las são produtos de pensamentos confusos. Não existem barreiras reais: e as coisas constituídas pelas barreiras de tempo e lugar não têm subsistência mais real do que as barreiras imaginativas que as constituem.

O primeiro resultado do pensamento claro é dissolver essas barreiras imaginativas: mostrar que a independência e o isolamento das coisas não são, em última instância, reais e, se tomados como definitivos, são a fonte do erro. A ciência - o primeiro estágio da inteligência revela o início da verdade, quando reconstrói o mundo como um sistema de propriedades 
comuns, ou (como deveríamos expressar) de leis universais. Substitui o mundo das coisas por um mundo que se torna necessariamente coerente por meio da interconexão do conteúdo de acordo com leis universais, ou princípios de síntese, que são eles próprios a articulação da inteligência científica. Em vez de este e aquele corpo, temos agora a natureza geral ou essência do corpo: corpo, concebido como um modo de Extensão, uma instância das leis da matemática, da mecânica e da física. Em vez de esta e aquela mente, temos a mente como tal: a essência da mente como um modo de Pensamento, uma instância das leis universais da psicologia e da lógica. E no lugar de este e aquele homem, temos o homem como tal: o homem como a natureza essencial, que é a "humanidade" de Pedro e Paulo; isto é, o homem como um modo de substância, uma instância das leis de Extensão e Pensamento.

Nosso eu nesse estágio é o que caracteriza todos os homens como tais, nossa humanidade. Temos um interesse e um ideal comuns, um amor comum pelo conhecimento. E viver uma vida comum ou social como meio de satisfazer esse amor. Podemos, neste estágio, justificar os deveres e direitos que constituem o ideal moral, quando este se identifica com a vida racional ou social. O cumprimento destes deveres, e a satisfação destes direitos, é bom para nós, porque é exigido por nossa razão para a realização de si mesma. A vida de acordo com a moralidade social é a vida de nós mesmos: nossa liberdade e nossa atividade. É, por assim dizer, o único alimento saudável para nós mesmos: e seria tolice rejeitá-lo pela vida da paixão, assim como seria loucura comer e beber veneno (E5p41esc).

Nesta vida racional, então, a natureza humana está se realizando, o intelecto humano está emergindo em si mesmo. Mas natureza humana e inteligência humana não devem ser entendidas como universais abstratos da imaginação. Elas são realidades concretas. E, como reais, elas estão (em nossa experiência) incorporados neste e naquele homem, nesta e naquela mente. Natureza humana é a natureza de Pedro e Paulo, na medida em que eles alcançam o seu melhor: inteligência humana é o pensamento deste e daquele homem de ciência ou filósofo, na medida em que seja verdade. E, no entanto, a natureza essencial e o verdadeiro pensamento de Pedro e Paulo, embora neles caracterizado e individualizado, são um e o mesmo por, e em, suas diferenças. Pedro e Paulo ganham personalidade para si mesmos, na medida em que compartilham a humanidade ou inteligência comum; e essa humanidade ou inteligência comum é a unidade de Pedro e Paulo, não a abstração de suas diferenças.

Pedro e Paulo permanecem distintos um do outro com as distinções ilusórias da consciência imaginativa. Eles nascem, vivem e morrem em diferentes condições locais e temporais. Em certa medida, eles devem permanecer à mercê da ordem comum da natureza - o esporte das paixões, que os leva ao conflito, ou pelo menos à divergência. No entanto, na medida em que compartilham da realização de sua natureza comum, eles entraram na herança de um tipo diferente de ser e de um nível diferente de individualidade.

Pois a mente que pensa verdadeiramente é una com a realidade que pensa. O que é verdade, é verdade independentemente do tempo: e a mente, que é pensamento verdadeiro, está livre de condições temporais e locais, ou seja, é ela própria um modo eterno. No estágio da ciência ("na medida em que ele entende") o homem é um modo eterno: Pedro e Paulo, ao atingir a humanidade comum, não são mais coisas particulares, mas mostram-se em seu ser necessário como modos eternos de Deus. E essa eternidade, que pertence a todas as coisas até agora, isto é, como uma coisa significa um objeto da ciência, uma natureza essencial, uma lei, uma verdade - , pertence à mente humana em um sentido mais amplo. Pois a mente humana não apenas é eterna, mas o é por si mesma: ela tem, e retém, a unidade da autoconsciência. Uma mente autoconsciente, seja qual for o caso com outros modos, é uma unidade, que não se dissolve em propriedades gerais antes da análise da ciência, mas compreende dentro de 
si (e para si mesma) em uma união necessária e viva todas as multiplicidades que a ciência nele revela. Uma mente que está claramente consciente de sua individualidade - que se conhece, de uma só vez, como uma consequência necessária do Pensamento de Deus e como um elemento necessário nesse Pensamento - é uma mente que atingiu o conhecimento intuitivo de si mesma: e nesse conhecimento ela é eterna com a mais plena eternidade de que o homem é capaz. Pois Deus é real nisso, não apenas como Deus é real em todas as mentes, mas nela como essa mente. No entanto, é essa mente como sendo um constituinte essencial da mente humana como tal: a individualidade da mente vem a ela não como um personagem que a separa de outras mentes ou pensamentos de Deus, mas como uma característica que a une a todos eles. É um pensamento que tem um significado único: mas seu significado único é dado a ele pelo e no contexto do pensamento de Deus. Ele e todos os intelectos, por seu significado individual, constituem o intelecto completo de Deus (E5p40esc).

\section{Referências}

GRZYMISCH, S. Spinoza's Lehren von der Ewigkeit und Unsterblichkeit. Breslau: Druck von T. Schatzky, 1898.

JOACHIM, H. H. A study of the Ethics (Ethica ordine geometrico demonstrata). Oxford: Clarendon Press, 1901.

POLLOCK, F. Spinoza: his Life and Philosophy. 2a ed. London: Duckworth \& Co., 1989.

TAYLOR, A. E. The Conception of Immortality in Spinoza's Ethics. Mind (N.S.), Oxford, v.5, n.18, 1896, p. 145-166.

\section{Sobre o tradutor}

Gionatan Carlos Pacheco

Doutorando em Filosofia pela Universidade Federal de Santa Maria (UFSM). 